\title{
Investigations to Model and Analyse the OHC Strength of Hybrid Composites
}

\author{
K. Mohamed Kaleemulla ${ }^{1, *}$, B. Siddeswarappa ${ }^{2}$, K. G. Satish ${ }^{2}$ \\ ${ }^{1}$ Department of Mechanical Engineering, University B.D.T. College of Engineering, Davangere 577004, India. \\ ${ }^{2}$ Department of Industrial and Production Engineering, University B.D.T. College of Engineering, Davangere 577004, India.
}

Received 7 May 2009; Revised 19 July 2009; Accepted 22 August 2009

\begin{abstract}
In recent years, the utilization of hybrid polymer matrix composite materials in many engineering fields has increased tremendously. The present investigation is devoted on fabric-reinforced hybrid composite laminates with different volume fractions of the constituent materials; epoxy resin, plain-woven glass fabric, and textile satin fabric. Fracture toughness of a material has immense importance in the determination of the resistance of the material to crack propagation. Hence this article explores the findings of the experimentation on the compressive strength and fracture toughness of fabric-reinforced laminates with $0 / 90^{\circ} \& \pm 45^{\circ}$ orientation with five notch configurations. The fracture toughness has been found to increase continuously with increased volumes of glass fabric and it is less dependent on notch size upto certain limit. Data collected during experimentations are validated using analysis of variance (ANOVA) technique. Percentage contribution of each parameter was evaluated using ANOVA technique with fiber content, orientation and notch size as input parameters, while the output parameter being the $\mathrm{OHC}$ strength of the laminate.
\end{abstract}

Keywords: Open hole compression, fracture toughness; woven hybrid composite; glass fabric; textile satin fabric.

\section{Introduction}

The most common method of assembling composite structure is by the use of mechanical fasteners, even though bolted joints are relatively inefficient. The stress concentration due to the hole will cause substantial reduction in strength and stability of notched composite laminates. The magnitude of this reduction varies considerably with a multitude of factors. All composite materials that exhibit a linear elastic stress-strain relationship to failure will be very sensitive to notches. Unlike metallic materials, the effects of the notch on strength will vary with the size of the notch but are relatively independent of notch geometry (Ref 1$)$.

Under compression, distribution of stresses occurs around the geometrical constraints like holes, reduced cross section, discontinuities, etc. The peak stress reaches a much larger magnitude than the average stress over the section. The stress is affected by the geometrical shape of the irregularities as well as by the dimensions of the irregularities. The presence of a hole in a specimen under load introduces three effects; first, there is an increase or concentration of stress at the root of the notch. Second, Stress gradient is set up from root of the notch toward the centre of the specimen and the third, a triaxial state of stress is produced at the notch root (Ref 2).

The hardness of the specimen as well as the geometrical shape and dimensions of notch affect the stress concentration factor. The factor of the material with higher hardness is larger than that of the

* E-mail address: kmdkaleemulla@gmail.com ISSN: 1791-2377 C 2009 Kavala Institute of Technology. All rights reserved. material with low hardness (Ref 3, 4). The notch root radius governs the relative elastic stress distribution near the notch root predominantly only. Both the maximum elastic stress and the notch root radius determine the yielded zone size near the notch root (Ref 5). The severity of stress concentration initiates propagation of cracks, causing the fracture of material. Fracture in all materials, brittle or ductile, homogeneous or composites, is governed more or less by discontinuities and imperfections, such as cracks, notches, inclusions or dispersed phases (Ref 6, 7).

Material strength may be correlated with its fracture energy, elastic modulus, and the size of the crack initiating the fracture. In this domain, the fracture toughness of the material has a major role in the determination of the fracture behaviour and resistance of the material to crack propagation under the influence of an external load. The material cannot be used without analysing the fracture behaviour or ultimate strength of structure. In assessing the strength of a structural element, fracture mechanics provides a greater insight when a crack-like defect is explicitly taken into account. Central to the process is the determination of stress intensity factor, which is a function of the geometry of the structure and the character of the load. The advent of fracture mechanics (Ref 8-10) has accelerated the methods for determination of crack growth rate and maximum allowable damage at limit load conditions.

Hence, the degradation of strength of composite materials in presence of central holes must be understood precisely under any situation for the wider application. Hybrid composites are finding 
wide applications in numerous structures of aircraft and spacecraft, as well as other cladding situations, and more particularly fabric-reinforced composites are used in case of thin-walled structures. Thus the understanding of the fracture behaviour and prediction of fracture toughness of composite materials have assumed greater importance. One of the accepted methods of analysing fracture behaviour is the application of Linear Elastic Fracture Mechanics (LEFM) (Ref 10), where the attention is focused on exploring the fracture mechanism at the crack tip of the fibre composites. A number of methods, both experimental and analytical, have been suggested by researchers (Ref 11-13) for the assessment of fracture strength as well as life prediction of composite materials.

Estimating the fracture load of notched plates has more or less been established and the influence of related parameters like width and thickness of specimen, notch geometry, notch angle, notch root radius, and notch depth have widely been studied (Ref 14-16). Thus, the determination of the stress intensity factor has become mandatory for solving the problems like residual strength analysis, fatigue crack growth rate and stress corrosion mechanism.

In this context, an extensive experimental investigation of open hole compression tests for different hole sizes, fibre orientations and fibre content has been carried out on fabric reinforced composite materials. In this article, the effects of selected parameters on fracture toughness $\left(\mathrm{K}_{\mathrm{I}}\right)$ have been determined.

\section{Methodology}

LEFM assumes that a linear elastic test specimen with an introduced crack will fracture under stress, and describes the energy changes that occur during the advance and growth of the original crack. Polymeric composite materials are described as having visco-elastic properties, according to which the parameter of paramount significance is the $\mathrm{K}_{\mathrm{I}}$, fractural toughness, the material's ability to withstand propagation of inherent defects (Ref 6, 17). The determination of the stress intensity factor has acquired considerable importance in the analysis of residual strength, fatigue crack growth rate and stress corrosion of composite materials, and thereby in determination of strength of the material. The stress intensity factor may be defined in terms of amplitude or strength of the stress singularity and is dependent on the state of stress at the crack tip. The stress intensity factor is therefore, obviously found to be dependent on radius of crack-tip, angle of crack and the distribution of the stresses for each mode, mentioned earlier. Thus, the applied load and size of the crack determines the stress intensity factor on the specimen (Ref 18).

In the case of flat compressive fractures, the forward mode as well as the parallel mode, crack surface displacements are found to be generally absent and therefore, the stress intensity factors in the opening mode may only be considered.

\section{Experimental \\ 3.1 Materials}

The present investigation has been carried out on three materials; epoxy resin, plain-woven glass fabric, and textile satin fabric. The matrix material was Araldite Epoxy Resin LY556 and hardener
HY951 mixed in appropriate ratio (10:1) with a room temperature curing cycle of 48 hours duration. Properties of the cured neat epoxy are listed in Table 1.

Table 1. Properties of the cured epoxy with neat formulation

\begin{tabular}{c|c|c|c|c}
\hline $\begin{array}{c}\text { Density, } \\
\mathrm{Kg} / \mathrm{m}^{3}\end{array}$ & $\begin{array}{c}\text { Tensile } \\
\text { Strength, } \\
\mathrm{MPa}\end{array}$ & $\begin{array}{c}\text { Tensile } \\
\text { Modulus, } \\
\mathrm{GPa}\end{array}$ & $\begin{array}{c}\text { Elongation, } \\
\%\end{array}$ & $\begin{array}{c}\text { Flexural } \\
\text { Strength, } \\
\mathrm{Mpa}\end{array}$ \\
\hline $1200-1250$ & $83-93$ & $31-33$ & $4.2-5.6$ & $115-125$ \\
\hline
\end{tabular}

In order to produce hybrid composite laminates, Plain weave E-glass fabric was used as the first reinforcement material. The candidate material has areal density range between $110-122 \mathrm{gsm}$, with 4 mil fabric and the fibers in wrap and fill directions being 60 X 58 respectively per inch length. The composition of the Eglass fabric is presented in Table 2 and the important properties are shown in Table 3.

Table 2. Composition

\begin{tabular}{c|c}
\hline Constituent & Percentage \\
\hline $\mathrm{SiO}_{2}$ & $52-56$ \\
$\mathrm{Al}_{2} \mathrm{O}_{3}$ & $12-16$ \\
$\mathrm{CaO}$ & $16-25$ \\
$\mathrm{MgO}$ & $0-5$ \\
$\mathrm{~B}_{2} \mathrm{O}_{3}$ & $8-13$ \\
$\mathrm{~K}_{2} \mathrm{O}$ & $0-1.5$ \\
$\mathrm{Na}_{2} \mathrm{O}$ & $0-1.5$ \\
$\mathrm{Fe}_{2} \mathrm{O}_{3}$ & $0.05-0.4$ \\
$\mathrm{TiO}_{2}$ & $0-.8$ \\
$\mathrm{~F}_{2}$ & $0-0.5$ \\
\hline
\end{tabular}

Table 3. Properties of E-glass

\begin{tabular}{c|c}
\hline Property & Value \\
\hline Density, $\mathrm{Kg} / \mathrm{m}^{3}$ & $2500-2550$ \\
Tensile Strength, $\mathrm{MPa}$ & $3400-3600$ \\
Tensile Modulus, $\mathrm{GPa}$ & $72-75$ \\
Elongation, \% & $4.2-4.8$ \\
\hline
\end{tabular}

The second reinforced fabric is cotton satin (sateen). The composition of the typical satin cloth selected for the investigation is $70 \%$ mercerized cotton and $30 \%$ polyester. The areal density of the satin fabric range between 230-254 gsm with at least 100 yarns per inch in the warp direction and at least 85 yarns per inch in the fill direction. The plain weave satin is preferred because it is a weave that already possesses good strength and can be reinforced to give a light weight highly serviceable fabric. The important properties of the satin fabric selected towards the second reinforcement material are presented in Table 4.

Table 4. Properties of Satin

\begin{tabular}{c|c|c|c|}
\hline $\begin{array}{c}\text { Density, } \\
\mathrm{Kg} / \mathrm{m}^{3}\end{array}$ & $\begin{array}{c}\text { Tensile Strength, } \\
\mathrm{MPa}\end{array}$ & $\begin{array}{c}\text { Tensile Modulus, } \\
\mathrm{GPa}\end{array}$ & $\begin{array}{c}\text { Elongation, } \\
\%\end{array}$ \\
\hline $920-1050$ & $750-900$ & $30-35$ & $2.2-3.8$ \\
\hline
\end{tabular}




\subsection{Specimen Preparation}

Bi-directional symmetric hybrid composite laminates with fabric reinforcement were fabricated at laboratory temperature in the shape of a rectangular plate by hand lay-up technique. Proper care was taken during fabrication of laminates to ensure uniform thickness, minimize voids in the material and maintain homogeneity. The laminates fabrication is by placing the fabric layers one over the other in the mold with matrix in between the layers, hand roller was used to distribute resin uniformly, compact plies, and to remove entrapped air. The surfaces of the mold were covered with a release film to prevent the lay up from bonding to the mold surface. The laminates were cured in room temperature $\left(25^{\circ} \mathrm{C}\right.$ and Relative Humidity 55\%), under constant pressure and left in the mold for 48 hours for complete curing. The laminates were cut to suit ASTM dimensions by a band saw cutter and the edges were trimmed.

Specimen preparation includes selection of different volume fractions for constituents; matrix material $40 \%$ for all samples, the volume fraction of glass fabric was between $15-45 \%$ in steps of $15 \%$ and the corresponding volume of satin fabric was estimated. The specimen preparation is in accordance with ASTM D6484 dimensions, with a notch centrally located in the form of drilled hole. Specimen configuration also includes selection of two fibre orientations i.e. $0 / 90^{\circ}$ and $\pm 45^{\circ}$, for each type of the specimen five notch diameters, 2, 4, 6, 8 and $10 \mathrm{~mm}$ were drilled centrally.

\subsection{Instrumentation}

The open hole compression test specimen with various notch sizes were loaded on a computer controlled Universal Testing Machine. The specimens were clamped in pin-loaded grips and subjected to displacement rate of $1.27 \mathrm{~mm} / \mathrm{min}$. The tests were closely monitored and conducted at room temperature. The load at which the complete fracture of the specimen occurred has been accepted as the critical load (Ref 19). The fracture toughness has been calculated by using the critical load for each specimen.

\section{Results and discussion}

The industries demand the database for information and further to develop testing and design standards. Therefore, the primary purpose of any material characterization is to investigate its behaviour under different mechanical loads. Experimentations have been carried out to characterize the candidate composite material under different loading conditions and with various specimen configurations, the analysis of the results and the influence of various parameters on the properties are summarized in the following sections.

\subsection{Physical properties}

ASTM D792 standards were used for density tests, rectangular samples of size $10 \mathrm{~mm}$ X $10 \mathrm{~mm}$ X $55 \mathrm{~mm}$ were used with thickness and width variations of $\pm 0.15 \mathrm{~mm}$ and $\pm 0.15 \mathrm{~mm}$, respectively. Distilled water at room temperature was used as the immer- sion fluid and the mass was measured using digital balance with a $10^{-4} \mathrm{~g}$ resolution. To obtain the mean value of density of each group, a total of thirty specimens such that a minimum of three specimens from each group were tested. As expected, the hybrid composites had no significant difference in density with respect to fiber orientation, this is attributed to the approximately same warp and fill count. However, the experiments show that the density of the laminates ranges from $1239.6 \mathrm{~kg} / \mathrm{m}^{3}$ to $1649.4 \mathrm{~kg} / \mathrm{m}^{3}$ for laminates with increase in glass content from $15 \%$ to $45 \%$, this is true because glass being the denser constituent among the selected materials and hence increases the sample density

ASTM D2734 standard was used to analyze the void percentage in composite laminate. Normally upto one percent of voids indicate a good composite, but practical difficulties increase the percentages of voids. The void content of a composite may significantly affect the mechanical properties. Higher percentages of voids usually mean lower fatigue resistance, greater susceptibility to water penetration and weathering and increased variation in strength properties. Knowing the densities of the constituents, the volume fractions of fiber, resin, and void were calculated based on two assumptions. The first assumption was that the mass of fiber in the composite was known (i.e., there is no fiber loss during manufacture). The second assumption is that the gas in any voids has the density of air, $1.29 \times 10^{-3} \mathrm{~g} / \mathrm{cm}^{3}$. The results show that void content varies between 2.6 to $4.8 \%$ for laminates with different percentages of reinforcement.

The fiber content in the composite laminates was analyzed by using ASTM D3171 standard, this method consists of dissolving the resin portion of a weighed composite specimen in a hot digestion medium, i.e., Nitric acid. The residue is filtered, dried, and weighed. The weight percent of fiber can be converted to a volume percent of by using the fiber and resin densities. Since in this study two types of reinforcements were used, to validate the above method a second method was also used to compare the results. In the second method fiber volume fraction of composite specimen was determined using standard method by burning small piece of hybrid composite of known weight and weighing the residue in the form of glass fibers. Comparing the results of both the tests, the deviation in volume fraction of five specimens in each case is between $0.5 \%$ to $1.1 \%$.

\subsection{Compressive Behaviour of Hybrid Composite Laminates}

The rectangular specimens with $6 \mathrm{~mm}$ thickness were cut to suit ASTM D3410 standards from the polymeric composite laminate. The Rectangular specimens were tested in a universal testing machine at a constant cross-speed and at room temperature. To minimize the effect of stress concentration, tabs with tapered ends were bonded on each side of the specimen. Normally for composites, the compression tests are designed to produce compressive property data for the material specifications, research and development (Ref 20). These data can be used to study the relationship among textile preform architecture, type of matrix, mechanical properties and failure modes (Ref 21). The presence of local defects, which are often difficult to characterize, also influences the failure in compression. Following discussion outlines the effects of various parameters on compressive strength. 

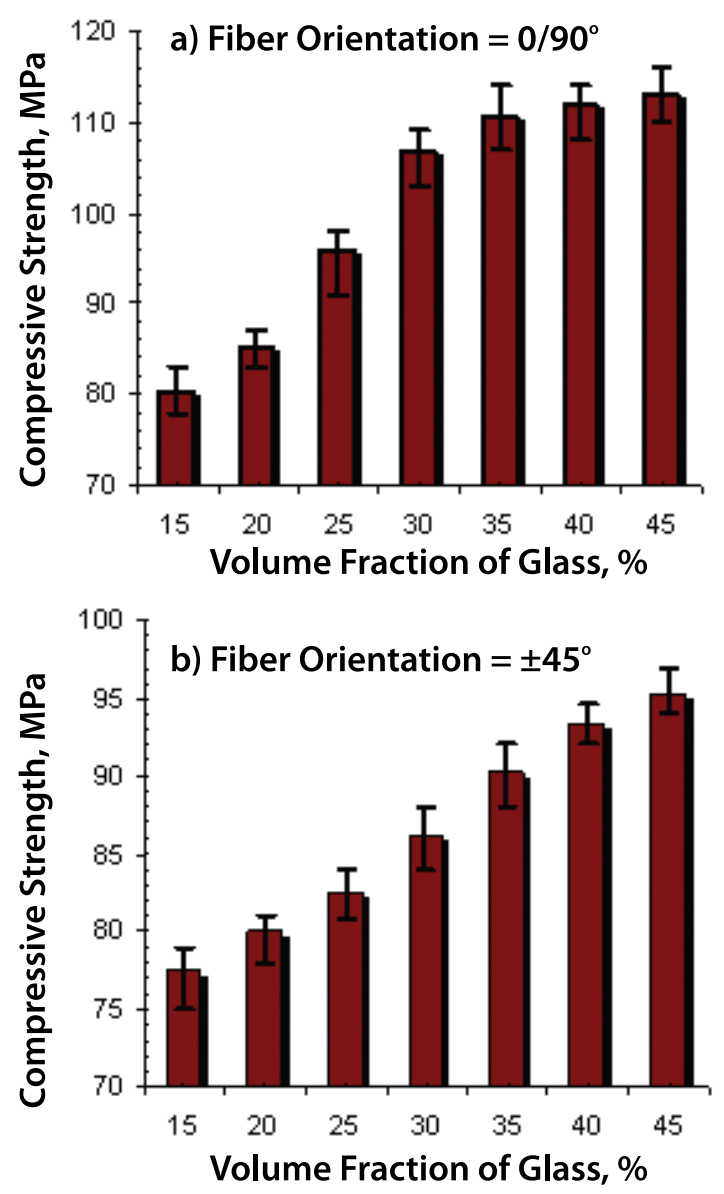

Figure 1. Influence of Fiber Content and Orientation on the Compressive Strength of Hybrid Laminates for (a) $0 / 90^{\circ}$ Orientation and (b) $\pm 45^{\circ}$ Orientation.

It is quite evident from the Fig. 1 that the compressive strength is superior for $0 / 90^{\circ}$ bidirectional fiber orientation, which is due to the basic reason that the longitudinal fibers directly absorb, transfer and distribute the load uniformly throughout the cross-section. Whereas the compressive strength in the other orientation is comparatively less, this difference is largely due to the fact that the fibers start slipping as they are subjected to the compressive load and hence the fiber to matrix load transfer is not uniform. Also the trends indicate that as glass fabric increases, compressive strength will also increase and it is true upto $30 \%$ of glass content. The change in compressive strength is almost negligible from $30-45 \%$ of glass content; this may be due to that as glass percentage increases specimen start behaving as brittle material.

\subsection{Open Hole Compression Test}

Open hole compression (OHC) strength is a good measure of consolidation quality, matrix properties and interface strength. Compression failure may occur in several modes ranging from buckling of the whole composite specimen to actual material compression at the microstructural level depending on material properties and loading scheme. Open hole compression test of the composite specimen is carried in accordance with ASTM D6484 standards, with a notch centrally located in the form of drilled hole. Composite specimens with central holes of different diameters ranging between $2 \mathrm{~mm}$ to $10 \mathrm{~mm}$ in steps of $2 \mathrm{~mm}$ were drilled on different specimens. The OHC test specimen with two fiber orientations $\left(0 / 90^{\circ}\right.$ and $\left.\pm 45^{\circ}\right)$ and various notch sizes were loaded on a computer controlled Universal Testing Machine. The experimental setup and testing conditions were same as that of the usual compression test. The results of the investigation are discussed in the following sections;

\subsubsection{Effect Fiber Volume Content and Orientation}

In this section the basic comparison is made between $\mathrm{OHC}$ strength of laminates for different percentages of glass, orientations and hole diameters, the results of the experimentation is plotted in Fig. 2. Trends straight away indicate that more the percentage of glass, superior will be the $\mathrm{OHC}$ strength and at the same time the greater the hole diameter, lesser will be $\mathrm{OHC}$ strength. This behaviour is true irrespective of fiber orientation, but $\mathrm{OHC}$ strength is less in case of $\pm 45^{\circ}$ orientation specimens compared to $0 / 90^{\circ}$ orientation specimens. The highest $\mathrm{OHC}$ strength obtained is $85 \mathrm{MPa}$ and 106 $\mathrm{MPa}$ respectively for $\pm 45^{\circ}$ and $0 / 90^{\circ}$ orientations, both in case of laminates with $45 \%$ glass content. For both the types of orientations, the severity increases as hole diameter crosses $4 \mathrm{~mm}$, this is probably due to increased stress concentration and smaller cross sectional area of resisting material.
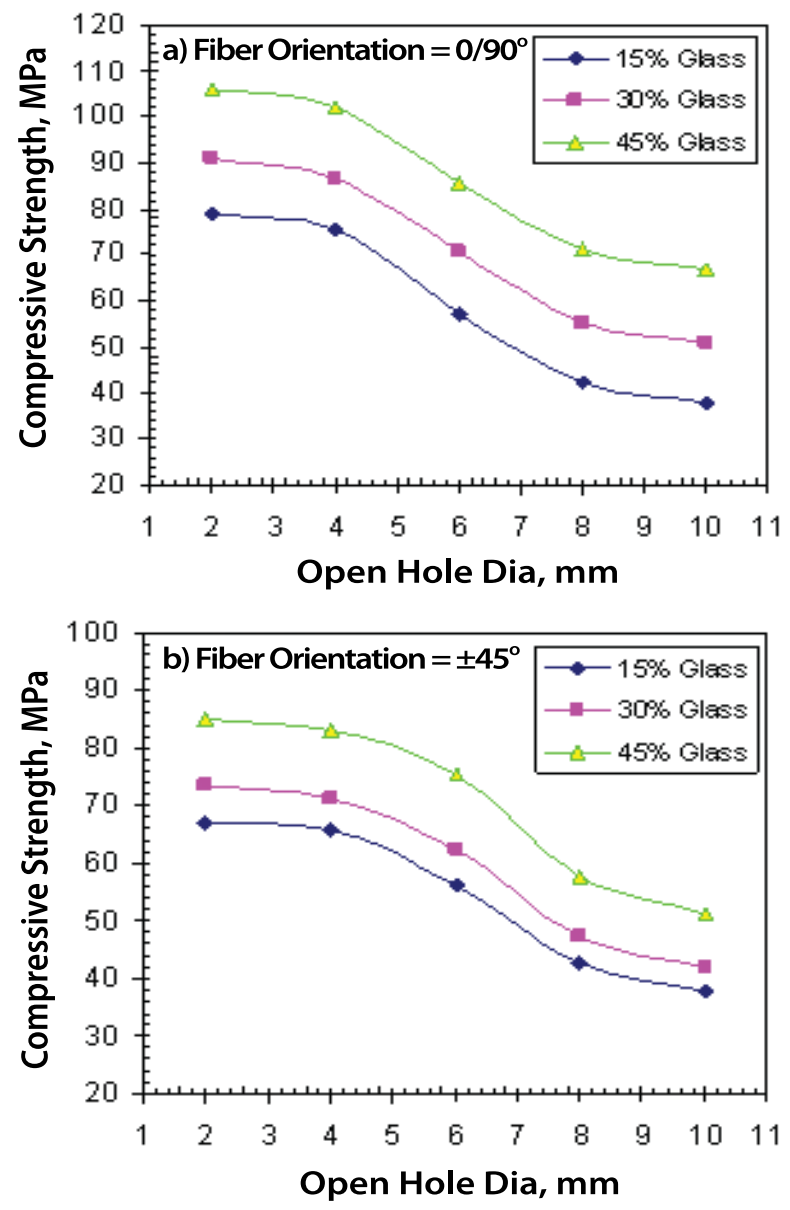

Figure 2. Effect of Hole Size and Glass Percentage on the OHC Strength of Hybrid Laminates for (a) $0 / 90^{\circ}$ Orientation and (b) $\pm 45^{\circ}$ Orientation. 


\subsubsection{Finite width correction factor}

OHC strength of all the laminates is plotted against width correction factor (W/d). Fig. 3 shows the plots for various samples with different glass contents and orientations. From the graphs, the significance of width factor can be observed, the laminates sustain higher compressive loads for width factor greater than five. This is attributed to the fact that as width factor reduces, the load bearing material reduces and hence smaller OHC strength. For width factors smaller than five, the load carrying material is less than $25 \%$ resulting in lesser $\mathrm{OHC}$ strengths. The laminates show approximately nonlinear relation upto $\mathrm{W} / \mathrm{d}=5$ and thereafter its approximately linear, this behaviour of the laminates reveal the fact that composites with load bearing material less than $25 \%$ exhibit higher stress concentration. The failure of these laminates is not only due to reduced load bearing area but also due to the difference in the Poisson's ratio of the matrix and fiber materials. Longitudinal compressive loading produces transverse tensile stresses within the matrix. These transverse tensile stresses can result in longitudinal cracks developing parallel to the fibers within a weak matrix. In addition, a weak interface can also fail under these transverse tensile stresses. Voids within the matrix or at the interface will act as stress raisers and increase the chance of longitudinal cracking. Upon further loading, these cracks will grow and result in transverse rupture of the composite.
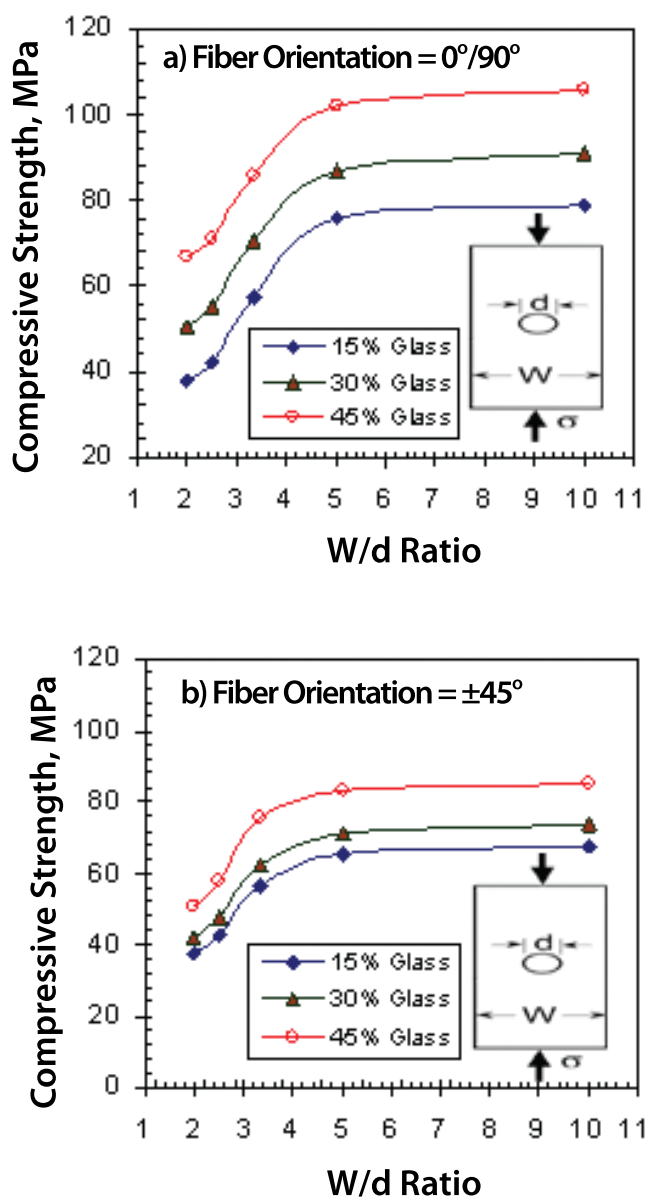

Figure 3. Width Correction Factor of $\mathrm{OHC}$ Laminates with different Glass Percentages for (a) $0 / 90^{\circ}$ Orientation and (b) $\pm 45^{\circ}$ Orientation.

\subsubsection{Effect of Glass Fiber Content on Fracture Toughness}

The $\mathrm{OHC}$ tests are used to evaluate the fracture toughness of composite laminates under compression, the results are shown in Fig. 4. Again as expected, superior fracture toughness for laminates with higher percentages of glass content is true irrespective of fiber orientation. The effect of hole diameter on fracture toughness is quite significant, it can be observed that there is a reduction in toughness as hole diameter increases from $4 \mathrm{~mm}$ for laminates with $15 \%$ glass content in $0 / 90^{\circ}$ orientation. Same trend is observed in case of specimen with $30 \%$ glass, but the margin of reduction is quite small. However, for laminates with $45 \%$ glass content the fracture toughness has never reduced, such a type of behaviour is mainly due to that glass is more tougher than the other two constituent materials. In case of $\pm 45^{\circ}$ oriented laminates the toughness has started declining for samples with hole diameter greater than $6 \mathrm{~mm}$, though the fracture toughness values are increasing but still these values are less than $0 / 90^{\circ}$ specimen for a given notch size and glass percentage. This behaviour may be due to off-axis loading, which results in shorter fiber length and reduced interface.
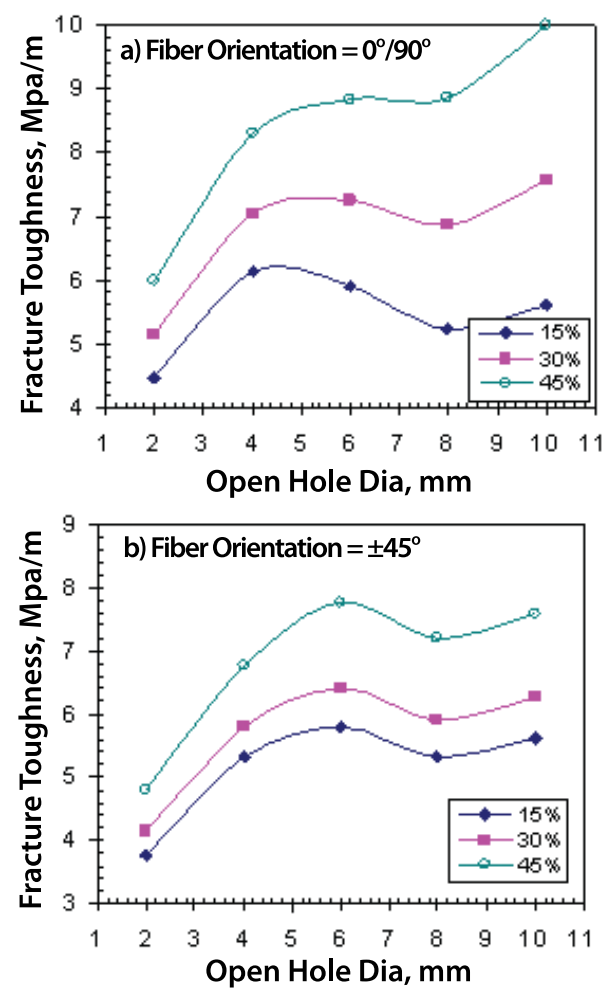

Figure 4. Effect of Hole Size on Fracture Toughness of Laminates under Compression for various Glass Percentages for (a) $0 / 90^{\circ}$ Orientation and (b) $\pm 45^{\circ}$ Orientation.

During longitudinal compressive loading, the fibers desire to buckle is resisted by the surrounding matrix; either the matrix must deform and/or the interface fail to allow buckling. Failure in strong glass-fiber reinforced composites initiates by micro-buckling of fibers that have the least lateral support due to free boundaries, voids, stress concentrations, or locally weak matrix. Micro buckling may progress into many different failure modes depending on the matrix and interface properties. The matrix and interface may be strong enough to withstand the Poisson's ratio induced transverse tensile 
stresses, but as fiber micro buckling begins, shear stresses are created at the interface. The interfaces may begin to fail in shear and lead to ultimate composite failure. Two modes of failure were visible in the tested specimens. Diagonal cracks in case of $\pm 45^{\circ}$ Orientation and transverse cracks for $0 / 90^{\circ}$ oriented laminates. On close observation there was no evidence of longitudinal cracks, but there exists damage in the form of delamination. The extent of delamination on laminates is not that severe, because the delamination is not propagated largely. The fractured specimen show cracks both transverse and diagonal pass through the drilled hole with angles approximately equal to the fiber orientation angles.

\subsection{Modeling of Compressive Strength}

For modeling of compressive strength, Multilevel Factorial Design was chosen, with three factors and 36 runs. The factors selected to study the response of Compression strength are glass volume fraction, fiber orientation and open hole diameter. Table 5 indicates the factors and their levels used in general linear model having 36 runs in multilevel factorial design. The compressive strength response was studied with the objective as larger is the better and the compressive test results were subject to the analysis of variance. The ANOVA technique was carried out for a level of significance of $5 \%$ that is the level of confidence is $95 \%$. For determining the significant effect of the parameters on the quality characteristics, F-test is used. Table 6 shows the results of ANOVA analysis for compressive strength.

Table 5. Process parameters for Compression Response

General Linear Model: Compression Strength Versus Volume Fraction, Orientation, Hole Diameter

\begin{tabular}{c|c|c|c}
\hline Factor & Type & Levels & Values \\
\hline $\begin{array}{c}\text { Volume Fraction, \% } \\
\text { Fiber Orientation, } \\
\text { deg }\end{array}$ & Fixed & 3 & $15,30,45$ \\
Fole Diameter, mm & Fixed & 2 & 0,45 \\
\hline
\end{tabular}

Table 6. Analysis of Variance Results for Compression Test

\begin{tabular}{|c|c|c|c|c|c|c|c|}
\hline $\begin{array}{l}\text { Source of } \\
\text { Variation }\end{array}$ & DF & SS & MS & $\mathbf{F}_{\text {Cal }}$ & $F_{0.05}$ & $\mathbf{P}, \%$ & $\begin{array}{l}\text { Signifi- } \\
\text { cance }\end{array}$ \\
\hline $\begin{array}{c}\text { Volume Frac- } \\
\text { tion (VF) }\end{array}$ & 2 & 3156.85 & 1578.43 & 368.48 & 4.10 & 21.54 & $\begin{array}{l}\text { Significant } \\
\text { at 95\% CL }\end{array}$ \\
\hline $\begin{array}{l}\text { Fiber Orienta- } \\
\text { tion }(\mathrm{FO})\end{array}$ & 1 & 1123.37 & 1123.37 & 262.25 & 4.96 & 7.66 & $\begin{array}{l}\text { Significant } \\
\text { at } 95 \% \mathrm{CL}\end{array}$ \\
\hline $\begin{array}{l}\text { Hole Diameter } \\
\text { (HD) }\end{array}$ & 5 & 9876.23 & 1975.25 & 461.12 & 3.33 & 67.39 & $\begin{array}{l}\text { Significant } \\
\text { at 95\% CL }\end{array}$ \\
\hline VF*FO & 2 & 228.29 & 114.15 & 26.65 & 4.10 & 1.56 & $\begin{array}{l}\text { Significant } \\
\text { at } 95 \% \mathrm{CL}\end{array}$ \\
\hline $\mathrm{VF} * \mathrm{HD}$ & 10 & 75.57 & 7.56 & 1.76 & 2.98 & 0.52 & $\begin{array}{l}\text { Insignificant } \\
\text { at } 95 \% \mathrm{CL}\end{array}$ \\
\hline $\mathrm{FO} * \mathrm{HD}$ & 5 & 153.07 & 30.61 & 7.15 & 3.33 & 1.04 & $\begin{array}{l}\text { Significant } \\
\text { at } 95 \% \mathrm{CL}\end{array}$ \\
\hline Error & 10 & 42.84 & 4.28 & & & 0.29 & \\
\hline Total & 35 & 14656.22 & & & & 100 & \\
\hline
\end{tabular}

$\mathrm{SS}=$ Sum of squares, $\mathrm{DF}=$ Degree of freedom, MS = Mean Square, $\mathrm{F}_{\text {cal }}=\mathrm{F}$-test calculated, $\mathrm{F}_{0.05}=\mathrm{F}$-value at $5 \%$ significance level and $\mathrm{P}=$ Percentage of contribution.
Table 6 shows the results of ANOVA analysis for compressive strength of laminates. The last column of the table shows the percentage contribution of each factor on the total variation indicating the influence on the result. It can be observed from the results that the interaction between the above factors does not have significant variation on the compressive strength of the composite laminates. It is clear from the ANOVA table that the glass volume fraction $(p=21.54 \%)$, Fiber orientation $(p=7.66 \%)$ and hole diameter $(p=67.39 \%)$ have significant influence on the compressive strength. The effect of the volume fraction and orientation is comparatively less, which indicates that hole diameter significantly controls the compressive strength of the composite laminate. However, the interaction between the factors is quite marginal and can be neglected and also the error associated in the ANOVA table was almost negligible because it is about $0.29 \%$. The Regression coefficient $\left(R^{2}\right)$ indicates that the predicted model explains $98.98 \%$ of variability in the compressive strength. $R^{2}$ value, which is very closer to unity, shows that the relationship between the compressive strength and other factors are fairly represented by the DOE model considered for design. The effect of the factors on compressive strength can be analyzed from the Fig. 5, it is clear that the hole diameter has significant influence on compressive strength compared to other factors. For laminates without any drilled hole the compressive strength was higher and at the same time for laminates with increased hole sizes, the compressive strength has decreased. Therefore higher compressive strength can be obtained with laminates having smaller hole diameters. This relation can be explained as hole diameter increases the stress concentration will increase and also the cross sectional area of the material reduce, resulting in failure of laminates at small loads.

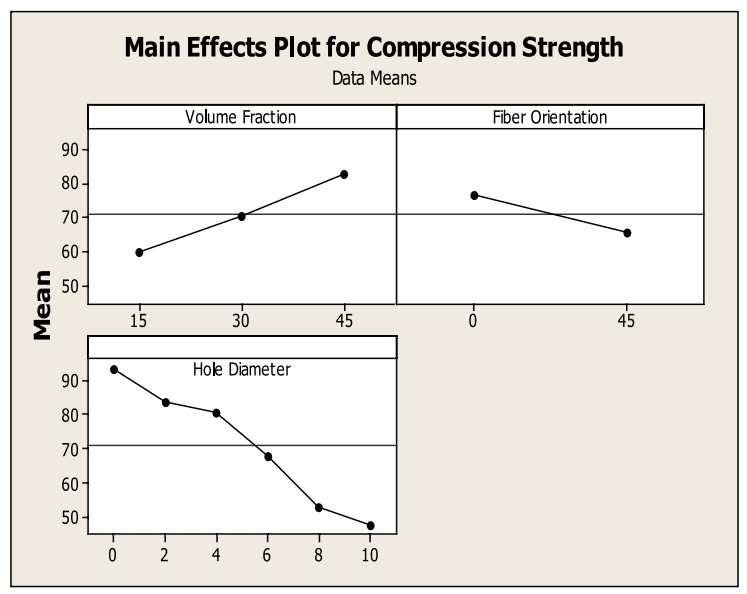

Figure 5. Main Effects plot for mean Compressive Strength on all factors

The above plot generalize the trends for the analysis purpose, to examine individual factor with all of its levels, the detailed interaction plot for compression strength is given in Fig. 6. The variation in compressive strength due to variations of factors is better understood by using contour and surface plots, hence to represent the effect of each of the factors at different levels of variation these plots are shown in Fig. 7. The contour plots indicate that the highest compressive strength is obtained when glass levels are high and hole diameter levels are low. This area appears at the lower right corner of the plot. The surface plot also show the same response, in addition it is possible to get a general idea of compressive strength at various levels of the factors. 


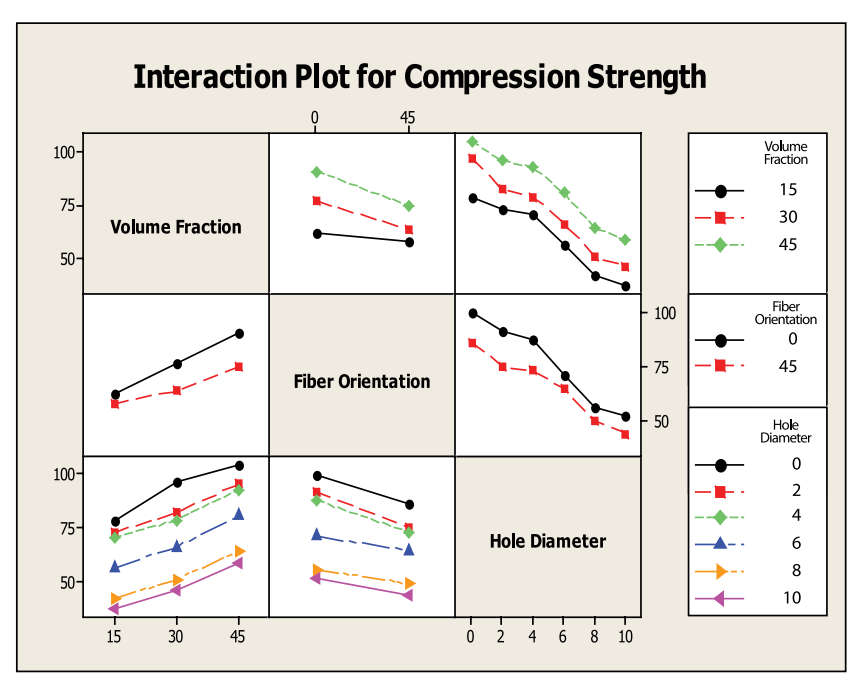

Figure 6. Interaction plot for Compressive Strength

\section{Contour Plot of Compression Strength vs Hole Diameter, Volume Fraction}

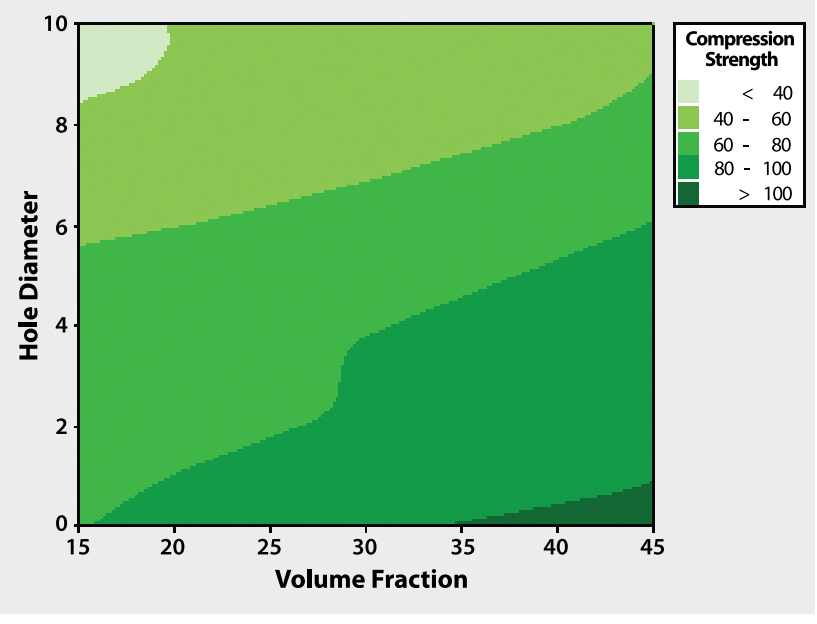

Surface Plot of Compression Strength vs Fiber Orientation, Hole Diameter

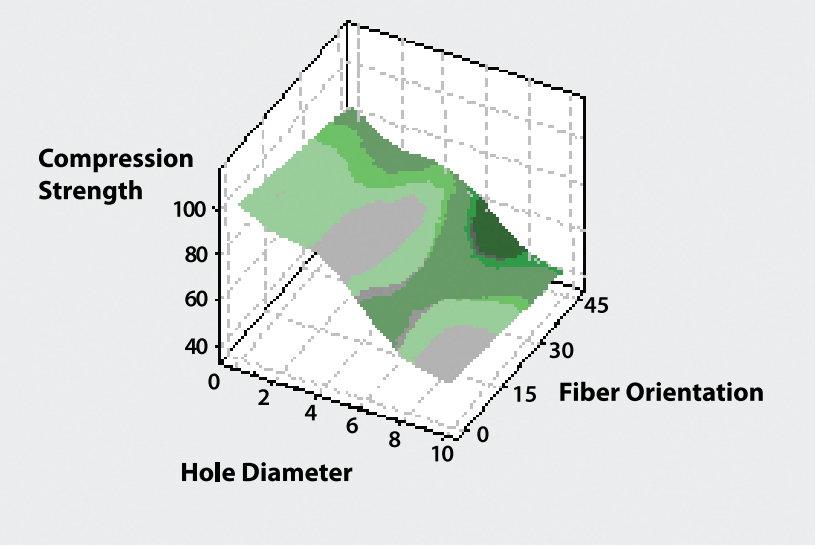

Figure 7. Contour and Surface plots for Compressive Strength

Residual plots that can be used to examine the goodness of model fit, Minitab has generated four types of residual plots as shown in Fig. 8. The Histogram shows two long tails indicating a skewed distribution and these points may be outliers. The standard error from the model obtained is $\mathrm{S}=2.206969$, this is a measure of model fit and it is measured in the units of the response variable and represents the standard distance data values fall from the regression line, or the standard deviation of the residuals. In this study, the standard error obtained is not that high which indicates model adequacy, hence the outlier points have little significance. The points in the normal probability plot have approximated a straight line, indicating normal distribution of residuals. Since there is no curvature at the tails, it can be said that the data used for the analysis is sufficient and goodness-of-fit is obtained. The verses fit show a random pattern of residuals on both sides of zero. Only two or three points lie far from the majority of points, indicating outliers. The points on either side of the zero line the residual density is approximately same, it is an indication that the predominance of positive residuals is same as that of the predominance of negative residuals. The residual verses plot shows random patterns on both sides of zero line, such patterns indicate the relation between the predictor and variables, otherwise indicating incorrect functional form of the model.

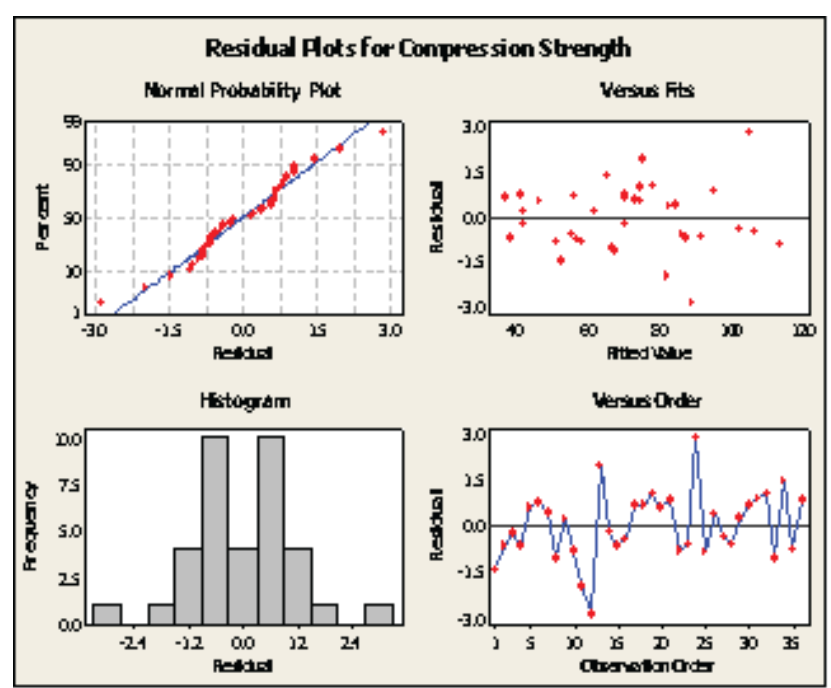

Figure 8. Residual plots for Compressive Strength

\section{Conclusions}

The experimental investigations have shown that, as the glass volume increases, the OHC strength will also increase but it is significantly dependent on the notch diameter. Upto hole $4 \mathrm{~mm}$ hole diameter, the reduction is marginal and thereafter the $\mathrm{OHC}$ strength reduces quite severely. Similar behaviour for fracture toughness $\left(K_{I}\right)$ was also observed for both the orientations. The finite width correction factor have also shown that the critical hole diameter is $4 \mathrm{~mm}$, indicating a minimum of $75 \%$ material requirement to with stand compressive loads and provide local fiber stabilities. ANOVA technique suggests that the hole diameter is significantly controls the $\mathrm{OHC}$ strength with a percentage contribution of about $67 \%$, while the less significant parameter being the orientation with approximately $7 \%$ contribution. 


\section{References}

1. "Composite Materials Handbook: Volume 1. Polymer Matrix Composites Guidelines for Characterization of Structural Materials", Department of Defense Handbook, MIL-HDBK-17-1F, 1, 2002, Chapter 7.

2. "Engineered materials hand book", Composites, ASM International, 1, 1987.

3. K. Taniuchi, The experimental analysis of yield stress at bottom of notch roots, Applied Stress Analysis, 1, 1990, pp. 234-242.

4. J.M. Whitney and R.J. Nuismer, Stress fracture criteria for laminated composites containing stress concentration, Journal of Computational Mathematics, 8(3), 1974, p.253.

5. H. Hyakutake and T. Hagio, The severity near the notch root of notched bars, Applied Stress Analysis, 1, 1990, pp. 243-249.

6. J. Lyons, Temperature Effects on Fractural Toughness of Polymeric Composites, Pittsburg State University-Kansas Technology Center, Pittsburg KS, 2003, p. 27.

7. K.L. Reifsnider, K. Liao, M. McCormic and A. Tiwari, Fibre fracture in continuous fibre ceramic composites: concepts and observations, Journa of Engineering for Gas Turbine and Power, ASME, 119(1), 1997, p.205.

8. G.G Chell, Developments in Fracture Mechanics-1, Applied Science Publication Ltd., London, 1979.

9. D. Broke, Elementary Engineering Fracture Mechanics, 4th ed., Martinus Nijhoff Publishers, The Netherlands, 1987.

10. H. Hyakutake, H. Nisitani and T. Hagio, Fracture criterion of notched plates of FRP, Journal of Japan Society of Mechanical Engineers, Series I, 32(2), 1989, p.300.

11. H.J. Konish and T.A. Cruse, Determination of fracture strength in orthotropic graphite/epoxy laminates, Composite Reliability, ASTM STP 580, 1975 , p.490.
12. F.A. McClintock and G.R. Irwin, Plasticity Aspects of Fracture Mechanics in Fracture Toughness Testing and it's Applications, ASTM STP 381, USA, 1984, p.84.

13. T.K. O'Brien, N.J. Johnson, D.H. Morris and R.A. Simonds, A simple test for the interlaminar fracture toughness of composites, SAMPE Journal, San Diego, 18(4), 1982, pp. 8-15.

14. J. Awerbach, and M.S. Madhukar, Notched strength of composite laminates: predictions and experiments - a review, Journal of Reinforced Plastics and Composites, 4, 1985, p. 105.

15. R.B. Pipes, R.C. Wetherhold and J.W. Gillespie Jr., Notched strength of composite materials, Journal of Composite Materials, 12, 1979, p.148.

16. Y. Weixing, On the notched strength of composite laminates, Journal of Composite Science and Technology, 45, 1992, p.105.

17. D.H. Morris and H.T. Hahn, Fracture of graphite/epoxy composites and composite materials: testing and design, Proceedings of the Conference of ASTM STP 617, USA, 1977, p.317.

18. H.J. Konish, J.L. Swedlow and T.A. Cruse, Experimental investigation of fracture in an advance composite, Journal of Composite Materials, 6(1), 1972, p.114.

19. W.F. Brown and J.E. Srawly, Plane strain crack toughness testing of high strength metallic materials, ASTM STP 410, 1966, p.292.

20. A. Dasgupta and R.K. Agarwal, Orthotropic Thermal Conductivity of Plain-weave Fabric Composite Using a Homogenization Technique, Journal of Composite Materials, 26(18), 1992, pp. 2736-2758.

21. S.Th. Georgopoulos, P.A. Tarantili, E. Avgerinos, A.G. Andreopoulos and E.G. Koukios, Thermoplastic polymers reinforced with fibrous agricultural residues, Polymer Degradation and Stability, 90(2), 2005, pp. 303312 . 